\title{
Base jurídica para a proteção dos conhecimentos tradicionais
}

Fernando Antonio de Carvalho Dantas*

\section{Resumo}

O presente artigo trata das bases jurídicas para a proteção dos conhecimentos tradicionais no âmbito conceitual do patrimônio cultural imaterial. As idéias estão estruturadas em três partes: referentes a transição paradigmática da proteção jurídica do patrimônio cultural; as bases jurídicas para a proteção dos conhecimentos tradicionais como patrimônio cultural e, por último, lança um olhar focado no conhecimento tradicional dos povos indígenas brasileiros.

Palavras-chave: Patrimônio cultural material e imaterial. Conhecimento tradicional. Povos indígenas.

\section{Legal basis for the protection of traditional knowledge}

\section{Abstract}

The present article deals with legal basis for the protection of traditional knowledge in the conceptual area of non-material cultural heritage. The ideas are structured in three parts: first, the paradigm transition of legal protection on cultural heritage; then, the legal bases for the protection of traditional knowledge as cultural heritage and, finally, the question of traditional knowledge of Brazilian indigenous people.

Key-words: Material and non-material cultural heritage. Traditional knowledge. Indigenous People.

1 A transição paradigmática na proteção jurídica dos bens culturais 


\subsection{Materialidade $\mathrm{x}$ imaterialidade}

Classicamente, no que concerne ao patrimônio cultural, a proteção jurídica recaia sobre bens de natureza material. Bens culturais, para o direito moderno ocidental clássico eram coisas concretas, palpáveis, registráveis e documentáveis. Esta configuração "material" dos bens culturais foi contemplada e amparada pelo direito nacional, na terceira década do século passado, a partir das prerrogativas traçadas por Mário de Andrade, que resultou na edição do Decreto-Lei 25 de 30 de novembro de 1937. Esse decreto-lei, ainda em vigor, trata da proteção do patrimônio histórico e artístico nacional, dando ênfase ao instituto jurídico do tombamento como forma de proteção jurídica desse patrimônio.

Entretanto, é importante salientar que, muito embora a legislação referenciada centralize a proteção em bens de natureza material, subjazem a esses bens elementos de natureza imaterial como a evocação, a representação e a lembrança a lugares, monumentos e fatos históricos relevantes para a cultura de um povo, o que os identifica, de forma irrenunciável, ao elemento subjetivo, imaterial. Segundo Souza Filho (1999, p.53), "por mais materiais que sejam existe neles uma grandeza imaterial que é justamente o que os faz culturais".

Com a promulgação da atual constituição federal, em 1988, a noção de patrimônio cultural foi ampliada com o reconhecimento dos bens de natureza material e imaterial portadores de referência à identidade, à ação, à memória dos diferentes grupos formadores da sociedade brasileira (Constituição Federal de 1988, art. 216).

A inclusão dos bens de natureza imaterial no rol de bens culturais merecedores de proteção jurídica, em sede constitucional, significa e aponta para um novo momento da historicidade do direito no que diz respeito ao não ocultamento das múltiplas e plurais representações culturais dos povos formadores do tecido social e, conseqüentemente, da memória brasileira.

\subsection{Passado $x$ presente}


Os bens culturais passíveis de proteção jurídica para sua preservação, na perspectiva anterior à constituição de 1988, referenciavam um passado materializado em monumentos representativos de momentos históricos relevantes para a cultura nacional, baseados na história oficial da cultura eurocentrista, com evidente velamento da dinâmica social e cultural dos povos formadores da cultura e da memória nacional. Assim, comumente, observamos o rol de edificações com valor histórico, artístico e paisagístico contemplar, exclusivamente, a produção material monumental da cultura branca ocidental.

Isto se dá no Brasil quando checamos as listagens dos edifícios e conjuntos urbanos edificados e tombados pelo Instituto do Patrimônio Histórico Nacional, pela rápida olhada em catálogos turísticos ou a vulgar informação das listas telefônicas.

Essa evocação ao passado com a prevalência dos marcos monumentais da história dos vencedores evidencia a exclusão institucionalizada de diferentes grupos formadores da cultura nacional como os povos indígenas, os negros e alguns imigrantes.

O rompimento do paradigma da exclusão jurídica, com o reconhecimento de bens culturais materiais e imateriais e a respectiva relação indissociável entre produção material de diversas origens e os conhecimentos que os fundamentam pela constituição de 1988, demonstra e impõe não somente o paradigma da inclusão dos diferentes modos de pensar, agir e fazer, mas, também, introduz, no âmbito do patrimônio cultural a ser preservado e protegido juridicamente, a dinâmica dos processos culturais e das práticas sociais.

Supera, como informa Fonseca (2003, p.56-78), a "pedra e o cal", da concepção clássica de patrimônio cultural para ampliá-lo ante a perspectiva dos "Tesouros humanos vivos" de Regina de Abreu (2003, p.81).

\section{As bases jurídicas para a proteção dos conhecimentos tradicionais no âmbito do patrimônio cultural}




\subsection{A constituição federal de 1988}

A Constituição Federal de 1988 ao tratar da ordem social (Título VIII), da educação, da cultura e do desporto (Capítulo III) e, especialmente da CULTURA (Seção II) reconhece os direitos culturais referentes ao patrimônio cultural brasileiro e as garantias do seu exercício de modo amplo e complexo, estipulando o seguinte:

Art. $215 \mathrm{O}$ Estado garantirá a todos o pleno exercício dos direitos culturais e acesso às fontes da cultura nacional, e apoiará e incentivará a valorização e a difusão das manifestações culturais.

$\S 1$. O Estado protegerá as manifestações das culturas populares, indígenas e afro-brasileiras, e das de outros grupos participantes do processo civilizatório nacional.

§ 2. A lei disporá sobre a fixação de datas comemorativas de alta significação para os diferentes segmentos étnicos nacionais.

Art. 216. Constituem patrimônio cultural brasileiro OS BENS DE NATUREZA MATERIAL E IMATERIAL, tomados individualmente ou em conjunto, portadores de referência $\grave{A}$ IDENTIDADE, À AÇÃO, À MEMÓRIA DOS DIFERENTES GRUPOS FORMADORES DA SOCIEDADE BRASILEIRA, nos quais se incluem:

I - as formas de expressão;

II - os modos de criar, fazer e viver;

III - as criações científicas, artísticas e tecnológicas;

IV - as obras, objetos, documentos, edificações e demais espaços destinados às manifestações artístico-culturais;

V - os conjuntos urbanos e sítios de valor histórico, paisagístico, artístico, arqueológico, paleontológico, ecológico e científico.

\subsection{A legislação infra-constitucional}

Mais de uma década após a promulgação da constituição de 1988, no ano de 2000 , norma infra-constitucional regulamentou a proteção jurídica do patrimônio cultural imaterial, ou seja, a proteção das formas de expressão, dos modos de fazer e viver, dos objetos, documentos, edificações e demais espaços destinados às manifestações artístico-culturais dos diferentes grupos formadores da identidade nacional. 
Por meio do Decreto 3.551 de 4 de agosto de 2000, o poder executivo instituiu o registro de bens culturais de natureza imaterial que constituem o patrimônio cultural brasileiro e, também, criou o Programa Nacional do Patrimônio Cultural Imaterial.

O registro desses bens culturais, constitui o marco jurídico da efetivação do reconhecimento constitucional do valor dos bens culturais imateriais para a cultura brasileira.

Dispõe a referida norma que o registro se dará nos seguintes livros:

1. LIVRO DE REGISTRO DOS SABERES;

2. LIVRO DE REGISTRO DAS CELEBRAÇÕES;

3. LIVRO DE REGISTRO DAS FORMAS DE EXPRESSÃO;

4. LIVRO DE REGISTRO DOS LUGARES;

\section{Um olhar focado no conhecimento tradicional}

Para Cristiane Derani (2002, p.155), o conhecimento tradicional associado é conhecimento da natureza, oriundo da contraposição sujeito-objeto sem a mediação de instrumentos de medida e substâncias isoladas traduzidas em códigos e fórmulas. É oriundo da vivência e da experiência, construído num tempo que não é aceito pela máquina da eficiência e da propriedade privada, mas cujos resultados podem vir a ser traduzidos em mercadoria geradora de grandes lucros, quando tomados como recursos da produção mercantil.

\subsection{Os direitos culturais como espaço de convergência e difusão dos direitos diferenciados indígenas}

[...] A representante dos Povos Indígenas no Conselho nacional de Combate à Discriminação Azelene Kaingáng falou da importância daquele momento e da emoção em ser pela primeira vez tratada pelo alto comando do Exército brasileiro como uma "igual", já que chegar num momento de "diálogo" pacífico foi extremamente difícil e desgastante para todos. Falou ainda da necessidade do Exército proteger os povos Indígenas enquanto brasileiros, já que em alguns conflitos como o que ocorre em Roraima com os arrozeiros, os índios sempre estão em desvantagem em relação aos não índios. Ressaltou ainda que a garantia e a defesa dos direitos humanos dos Povos Indígenas é perfeitamente compatível com a defesa da soberania do País, 
por isso a necessidade de se construir um termo de convivência entre Povos indígenas e o Exército. Falou da violação dos direitos das mulheres e dos processos judiciais de reconhecimento de paternidade que estão na justiça, solicitando que o exército acelere a apuração de responsabilidade dos seus membros envolvidos nesses processos. (KAINGANG, 2003)

O histórico ocultamento e invisibilidade dos povos indígenas, dos negros e de grupos formadores do tecido social brasileiro, sempre estiveram vinculados aos seus diferenciados modos de ser, de pensar e de agir. No direito positivado enquanto "poder simbólico" (1) da sociedade branca dominante, esses modos indígenas de viver, ou seja, de conhecimento e de organização social, foram empregados com dinamicidade histórica, refletindo e legitimando, normativamente, os pré-juízos das sutis adjetivações do senso comum de cada época, ao tratá-los de bárbaros, selvagens ou, genericamente, índios, no caso dos povos indígenas, ou de culturas exóticas, no caso de outros segmentos formadores da cultura nacional.

A Constituição de 1988 avançou significativamente ao reconhecer os índios, suas indissociáveis organizações sociais, seus costumes, línguas, crenças e tradições, aliados ao espaço territorial de habitação.

Muito embora tenha mantido a indeterminação terminológica (índios), esse reconhecimento constitucional implica um novo paradigma para a subjetividade indígena como coletiva e diferenciada. Implica, também, uma pluralização do direito ao impor, pela força normativa da Constituição, abertura e conseqüentes desdobramentos no que tange à configuração do contexto social, político, jurídico e institucional dos direitos diferenciados indígenas decorrentes desse reconhecimento.

O primeiro desdobramento necessário refere-se à noção de espaço. Como teoriza Herrera Flores, os direitos devem ser estudados, ensinados e praticados a partir das diferentes "posições" que ocupam em contextos determinados. Assim, o espaço dos direitos não significa uma noção física, um lugar. Significa uma posição, "a construção simbólica de processos nos quais se criam, reproduzem e transformam os sistemas de 
objetos e os sistemas de ações". (2000, p.60-61, tradução nossa) (2)

O contexto ou o "espaço" atual dos direitos indígenas e de povos historicamente excluídos é o da efetivação, da concreção do reconhecimento constitucional e de direitos consagrados em documentos jurídicos internacionais. Portanto, a configuração do desenho e da edificação de novas relações sociais envolve os povos indígenas, a sociedade e o Estado brasileiros e as projeções externas, no âmbito dos organismos multilaterais.

A efetividade do reconhecimento constitucional dos direitos coletivos à diferença, as relações interétnicas com autonomia, a participação dos povos indígenas nos âmbitos institucionais do Estado e a articulação local/global compõem e associam o sentido emancipatório dos princípios acima anotados constituindo, no momento atual, um complexo ponto de partida para a construção de processos de lutas contra a dominação.

Para Sousa Santos e Nunes,

multiculturalismo, justiça multicultural, direitos coletivos, cidadanias plurais são hoje alguns dos termos que procuram jogar com as tensões entre a diferença e a igualdade, entre a exigência de reconhecimento da diferença e de redistribuição que permita a realização da igualdade. (2003, p.25)

Nesse sentido os autores propõem um conjunto de cinco teses sobre multiculturalismos emancipatórios e escalas de lutas contra a dominação, fundamentadas em estudos de casos referentes aos movimentos contra-hegemônicos dos povos indígenas e de setores marginalizados e organizados nas sociedades atuais, buscando noções mais inclusivas e, ao mesmo tempo, respeitadoras da diversidade e das conseqüentes diferenças de concepções de vida e de mundo que estas representam, contrárias às noções reducionistas e eurocêntricas de cultura, justiça, direitos e cidadania:

1) Diferentes coletivos humanos produzem formas diversas de ver e dividir o mundo, que não obedecem necessariamente às diferenciações eurocêntricas como, por exemplo, a que divide as práticas sociais entre a economia, a sociedade, o Estado e a cultura, ou a que separa 
drasticamente a natureza da sociedade. Está em curso uma reavaliação das relações entre essas diferentes concepções do mundo e as suas repercussões no direito e na justiça.

2) Diferentes formas de opressão ou de dominação geram formas de resistência, de mobilização, de subjetividade e de identidade coletivas também distintas, que invocam noções de justiça diferentes. Nessas resistências e suas articulações locais/globais reside o impulso da globalização contra-hegemônica.

3) A incompletude das culturas e das concepções da dignidade humana, do direito e da justiça exige o desenvolvimento de diálogo (a hermenêutica diatópica) que promovam a ampliação dos círculos de reciprocidade.

4) As políticas emancipatórias e a invenção de novas cidadanias jogam-se no terreno da tensão entre igualdade e diferença, entre a exigência de reconhecimento e o imperativo da redistribuição.

5) O sucesso das lutas emancipatórias depende das alianças que os seus protagonistas são capazes de forjar. No início do século XXI, essas alianças têm de abranger movimentos e lutas contra diferentes formas de opressão. (SOUSA SANTOS; NUNES, 2003, p.59-66)

Os povos indígenas em suas lutas cotidianas pelo respeito aos seus direitos diferenciados, armam-se desses direitos (3), para enfrentar os novos espaços e contextos de exercício da sua cidadania diferenciada multicultural e cosmopolita, substituindo a dominação pela emancipação. Essa substituição implica superação do ambiente opressor das formas de poder tanto nacional como mundial, pela participação democrática dos povos indígenas, em um sistema de trocas iguais. (4)

O contexto propício para tal, segundo Cullen (2003, p.251-267), situa-se na "construção do espaço público intercultural", baseado no diálogo e na razoabilidade.

A construção desse espaço público intercultural dos direitos diferenciados, que, pelos processos de lutas, supere as trocas desiguais e possibilite o desenvolvimento integral dos povos indígenas, sem opressão ou qualquer forma de dominação, se constitui no desafio político e jurídico da atualidade. O espaço é a luta pelo reconhecimento, proteção e efetivação plena dos direitos intelectuais desses povos, acossados pela fúria mercantilista.

Os direitos intelectuais, quais sejam, os direitos culturais do conhecimento, dos modos de ser, fazer e viver dos povos indígenas e dos grupos formadores da cultura nacional, 
configuram a fronteira contemporânea, o espaço de lutas pelos direitos, onde um novo modo democrático de relação, fundado na emancipação, possa, pelo exercício de direitos, vencer os processos históricos de espoliação.

Assim, os direitos intelectuais desses povos, cuja natureza coletiva situa-se nos conhecimentos tradicionais, segundo Derani, são associados ao meio, ao espaço territorial de desenvolvimento da vida e da cultura de cada povo:

o conhecimento tradicional associado é conhecimento da natureza, oriundo da contraposição sujeito-objeto sem a mediação de instrumentos de medida e substâncias isoladas traduzidas em códigos e fórmulas. É oriundo da vivência e da experiência, construído num tempo que não é aceito pela máquina da eficiência e da propriedade privada, mas cujos resultados podem vir a ser traduzidos em mercadoria geradora de grandes lucros, quando tomados como recursos da produção mercantil. (2002, p.155)

As sociedades indígenas e suas formas coletivas de pensar o mundo e o meio em que vivem, foram amplamente estudadas por Lévi-Strauss (1970), que denominou essa articulação de idéias de "pensamento selvagem". Isto aplica-se às populações tradicionais. O autor encontrou uma lógica nesse pensamento, um conhecimento objetivo e fundamental das relações do homem com o meio e entre si. Deste modo, o pensar indígena, contrariamente às posições meramente funcionalistas, não se motiva unicamente nas estratégias de satisfação das necessidades, pois organiza seu mundo social e simbólico. (5)

O confronto do homem com o meio (sujeito-objeto), permeado com aportes mágicos e simbólicos - sempre presentes na formulação do conhecimento tradicional - dá conta da complexa e histórica experiência da vida indígena, contextualizada a cada realidade específica (6). Esses atributos conformam o que Morin almeja para uma nova configuração do conhecimento científico, baseada na transdisciplinaridade. Afirma o autor que: "só a razão aberta, capaz de trabalhar com o irracional, saberá vencer o desafio da complexidade" (1990). A complexidade é característica da organização social dos povos indígenas e da elaboração do conhecimento. 
Nessa mesma linha de pensamento, Posey afirma, após longos estudos sobre a cultura e o conhecimento tradicional associado ao patrimônio genético do povo Mebêngôkre, conhecidos como Kayapó, que esse conhecimento "é um sistema integrado de crenças e práticas [...] existe muita informação compartilhada em uma aldeia Mebêngôkre, apesar de haver, também, muitos especialistas". (1989, p.12)

As sociedades indígenas como fontes produtoras de conhecimento para o mundo podem oferecer, desde seus saberes, alternativas às complexas questões do cenário políticoeconômico-social-cultural e científico da atualidade. O grande problema que se afronta, reside na forma como essa alternativa poderá chegar a ser utilizada pela humanidade como um todo, respeitando-se os direitos dessas sociedades.

A economia capitalista, baseada na eficiência e no lucro fácil, e ancorada no projeto político neoliberal que sustenta mundialmente o processo de globalização, investe nesse sentido. Entretanto, reserva às instituições multilaterais e aos procedimentos formais estatais, o modo de acesso a esses saberes, fundados nos sistemas de propriedade intelectual.

Os saberes dos povos indígenas, assim como os de toda comunidade tradicional, conforme visto anteriormente, constituem fenômenos complexos construídos socialmente a partir de práticas e experiências culturais, relacionadas ao espaço social, aos usos, costumes e tradições. Por ser coletivamente construído, possuem características marcantes de relações compartilhadas, de intercâmbios, de solidariedades, o que os difere, substancialmente, do caráter individualista da propriedade privada.

Esses conhecimentos constituem direitos coletivos dos povos indígenas, posto que, por um lado, são relacionados à organização social, aos usos, costumes, tradições e ao território, portanto, vinculados à essência do existir desses povos; por outro, são direitos reconhecidos constitucionalmente, conforme já foi visto. Assim, a natureza coletiva desses direitos os contrapõe ao caráter individualista, privatista e exclusivista dos direitos de 
propriedade intelectual (7), na forma em que estes se encontram formalizados e "padronizados" nos instrumentos jurídicos internos e externos. (8)

A legislação nacional sobre o tema, consubstanciada na Medida Provisória n. ${ }^{\circ} 2.186$ 16, de 24 de agosto de 2001, vincula-se ao caráter individualista quando trata do acesso aos conhecimentos tradicionais, abrindo a possibilidade da apropriação privada por terceiros acessantes. Segundo Derani (2002, p.153-163), "são sujeitos detentores dos objetos cujo acesso é regulado pela MP, as comunidades indígenas e locais". Para a autora, acessar é apropriar-se, portanto, a regulação brasileira sobre o acesso aos conhecimentos tradicionais associados ao patrimônio genético, configura uma privatização, por sujeitos que não os seus legítimos detentores, da biodiversidade e do conhecimento sobre esta.(9)

Carneiro da Cunha parte do pressuposto de que o conhecimento indígena é passível de ser explorado economicamente, sem que isto interfira negativamente na organização social desses povos, uma vez que, analogicamente, outras figuras legais estranhas ao mundo indígena são imprescindivelmente utilizadas, como a proteção do direito à terra, por exemplo. Afirma a autora que:

os antropólogos não teriam percebido que conceitos estranhos ganham novos usos e são estrategicamente apropriados pelas sociedades "fracas"? Que eles podem, uma vez usados como armas, serem mantidos à distância, guardados nas fronteiras, dentro das esferas que não se misturam a instituições internas? Ou ainda expressos em novas instituições que seguem regras diferentes do mundo como um todo? O conhecimento pode ser colocado no mercado mundial por sociedades indígenas e ainda ser distribuído em diferentes caminhos no interior do mesmo grupo (como nas academias tradicionais). (1999, p.95)

Essa profícua discussão tem ocupado espaço nos debates internacionais, principalmente no Fórum Indígena sobre a Diversidade Biológica, reunião que se realiza paralelamente à Conferência das partes da Convenção sobre Diversidade Biológica CDB, especialmente do Grupo de Trabalho sobre a aplicação do artigo 8-j e disposições conexas. 
A Convenção sobre Diversidade Biológica se constitui em instrumento jurídico de direito internacional, firmado pela maioria dos estados participantes da reunião das Nações Unidas, realizada no Rio de Janeiro, em junho de 1992. São três os objetivos da Convenção: a conservação da diversidade biológica, o uso sustentável de suas partes constitutivas e a repartição eqüitativa dos benefícios advindos do aproveitamento e uso dos recursos genéticos.

No que concerne ao reconhecimento dos direitos intelectuais dos povos indígenas e das populações tradicionais sobre o conhecimento tradicional associado ao patrimônio genético, dois dispositivos da CDB se constituem em instrumentos de grande importância porque permitem a discussão do tema: o Art. 8-j, que determina aos Estados membros, de acordo com as legislações nacionais, o respeito, a preservação e a manutenção do conhecimento tradicional, associado das inovações e práticas dessas populações, e o Art. 15, que garante aos Estados sua soberania sobre os recursos genéticos, ao mesmo tempo em que estipula modos de facilitar o seu acesso, instituindo como condição ao acesso o consentimento prévio fundamentado.

Pela CDB, cabe aos Estados darem este consentimento. Entretanto, de acordo com a Constituição de 1988 , Art. 231 , $\S \S 2 .^{\circ}$ e $3 .^{\circ}$, há a garantia exclusiva de usufruto pelos povos indígenas, das riquezas do solo e do sub-solo de suas terras. Assim, a efetividade da norma constitucional se impõe, por extensão ao disposto nos casos excepcionais de exploração do potencial hídrico e mineral, para os quais exige-se autorização do Congresso Nacional, condicionada à manifestação favorável da comunidade indígena afetada.

Assim, sendo as comunidades indígenas usufrutuárias exclusivas do seu patrimônio genético, deverão, elas e somente elas, opinar sobre o consentimento de que trata a Convenção (10). É neste sentido que, entre as reivindicações dos povos indígenas, ressalta-se a necessidade de participação efetiva nas deliberações da Conferência, como um dos pontos principais de inserção da voz e legitimidade desses povos e das populações locais nos organismos normativos institucionais, tanto nacionais como 
internacionais. (ONU, p.19-20)

A busca de respostas satisfatórias seja do ponto de vista legal, consubstanciadas no Estado plural e no seu correspondente pluralismo jurídico - o que exige uma modificação estrutural no conceito clássico de Estado e de cidadania -, ou na definição de âmbitos supranacionais heterogêneos e alternativos, governados solidariamente pelos povos indígenas, constitui imperativo inadiável porque significa a ruptura com o tempo da espoliação dos direitos territoriais e culturais dos povos indígenas, implicando no reconhecimento, proteção e efetivação desses direitos.

Os conhecimentos tradicionais indígenas associados ao patrimônio genético configuram direitos coletivos de cada povo, são direitos culturais (SOUZA FILHO, 1998, p.184). Como tais, são protegidos constitucionalmente pela ordem jurídica brasileira e pelo conjunto integrado dos direitos humanos.

\section{Notas}

(1) Para Pierre Bourdieu o direito é um "poder simbólico" que tem a força de impor, nas sociedades modernas, a construção da realidade social, a definição do mundo social. BOURDIEU, Pierre. Poder, derechos y clases sociales. Bilbao: Desclée de Brouwer, 2000. p.123-125.

(2) Texto original: "Hablar de espacio ya no consiste em hacerlo de contextos fisicos o lugares, sino de la construcción simbólica de procesos en los que se crean, reproducen y transforman los sistemas de objetos y los sistemas de acciones". HERRERA FLORES, Joaquín (org.). Hacía una visión compleja de los derechos humanos. In: HERRERA FLORES, Joaquín (org.) El vuelo de Anteo: derechos humanos y crítica de la razón liberal. Bilbao: Desclée de Brouwer, 2000, p.60-61.

(3) Usando a expressão de Andrés García Inda na introdução a Poder, Derecho y Clases Sociales. O autor afirma que "o campo jurídico é um jogo onde é necessário armar-se de direito para ganhar", como correlata à proposição de Pierre Bourdieu de que "no campo científico é preciso armar-se de razão para ganhar". GARCíA INDA, Andrés. Introducción. In: BOURDIEU, P., op. cit., p.39.

(4) Segundo Boaventura de Sousa Santos, a forma de poder do espaço mundial gira em redor da troca desigual, pelo poder da exploração e fetichização das mercadorias. Essa forma de poder constela-se, "decisivamente com a dominação, como resulta evidente das relações entre transnacionalização da economia e os Estados-nação". SOUSA SANTOS, Boaventura de. A crítica da razão indolente: contra o desperdício da experiência. In: Por 
um novo senso comum: a ciência, o direito e a política na transição paradigmática. 4.ed. São Paulo: Cortez, 2002. p.288-289. v.1.

(5) Entendemos que essa lógica do pensar indígena coloca os conhecimentos oriundos desse pensar no mesmo nível de importância do conhecimento científico, em valor, e, também, do ponto de vista explicativo, porque segue complexos procedimentos de estruturação que se diferem da ciência clássica por serem informais, coletivos e compartilhados quanto à origem, e por não adotarem mecanismos e regras universais de sistematização.

(6) Segundo Lymert Garcia dos Santos, algumas características muito específicas do conhecimento tradicional são extremamente relevantes na sua confrontação com o conhecimento técnico-científico-formal: "1) O conhecimento tradicional difere fundamentalmente do conhecimento tecno-científico moderno, por integrar uma outra cultura; 2) que não é e nunca foi concebido como propriedade de alguém, não podendo portanto ser alienado; 3) que por ser coletivo, tanto sincrônica quanto diacronicamente, só pode ser protegido através de um direito coletivo; 4) que por ser de outra natureza, inalienável e coletivo, deve ser regido por um regime jurídico sui generis e não pela propriedade intelectual; 5) que seu valor não se reduz à dimensão econômica, conservando ainda as dimensões social, cultural, ambiental, técnica, cosmológica; 6) que não tendo valor exclusivamente econômico, não pode ser referido apenas a uma questão de repartição de benefícios dele decorrentes; 7) que a sua proteção é imprescindível da conservação da bio e da sociodiversidade; 8) que em virtude do seu caráter específico e de sua fragilidade perante o conhecimento tecno-científico moderno só pode ser preservado se os povos que o detém puderem mantê-lo e desenvolve-o, negando inclusive o acesso aos recursos a eles associados quando julgarem necessário e, 9) que o conhecimento tradicional não pode ser reduzido à condição de matéria prima disponível para a valorização do conhecimento e do trabalho biotecnológico.". SANTOS, Lymert Garcia. Propriedade intelectual ou direitos intelectuais coletivos? In: ARAÚJO, Ana Valéria; CAPBIANCO, João Paulo (Orgs.). Biodiversidade e proteção do conhecimento de comunidades tradicionais. Documentos do ISA - Instituto Socioambiental, n.2, 1996, p.22.

(7) Para Andressa Caldas, "a questão que se impõe é de como lançar mão de um sistema que se funda no reconhecimento de proteção a título privado, individual e exclusivo para regular o conhecimento tradicional, sem limitá-lo ou ainda, sem (direta ou indiretamente) interferir na organização social e política das comunidades que detém esses saberes?" CALDAS, Andressa. Regulação jurídica do conhecimento tradicional: a conquista dos saberes. Dissertação (Mestrado em Direito das Relações Sociais), Curso de Pós-graduação em Direito, Universidade Federal do Paraná, Curitiba, 2001, p. 117.

(8) BRASIL. Medida Provisória n. ${ }^{\circ} 2.186-16$, de 24 de agosto de 2001. Regulamenta o inciso II do $\S 1^{\circ}$ e o $\S 4^{\circ}$ do art. 225 da Constituição, os arts. 1ำ, 8a alínea "j", 10, alínea "c", 15 e 16, alíneas 3 e 4 da Convenção sobre Diversidade Biológica, dispõe sobre o acesso ao patrimônio genético, a proteção e o acesso ao conhecimento tradicional associado, a repartição de benefícios e o acesso à tecnologia e transferência de tecnologia para sua conservação e utilização, e dá outras providências.

(9). "Direitos de propriedade são atribuições individuais. Porém, o conhecimento pode ser construído pela tradição e pela vivência coletiva, em oposição à razão individualista". (DERANI, Cristiane. Patrimônio genético e conhecimento tradicional associado: considerações jurídicas sobre seu acesso. In, LIMA, André. (org.). O direito para o Brasil socioambiental. Porto Alegre: Sérgio Antonio Fabris Editor, 2002, p. 153-163). 
(10) Neste sentido ver: SANTILLI, Juliana. A proteção aos direitos intelectuais coletivos das comunidades indígenas brasileiras. Disponível em:: <http://www.socioambiental.org/website/bio/doc.htm>.

\section{Referências Bibliográficas}

ABREU, Regina. "Tesouros humanos vivos" ou quando as pessoas transformam-se em patrimônio cultural - notas sobre a experiência francesa de distinção do "Mestre da Arte". In: ABREU, Regina; CHAGAS, Mário (orgs.). Memória e patrimônio, ensaios contemporâneos. Rio de Janeiro: DP\&A, 2003.

BOURDIEU, Pierre. Poder, derechos y clases sociales. Bilbao: Desclée de Brouwer, 2000.

BRASIL. Constituição Federal (1988). Medida Provisória n. ${ }^{\circ}$ 2.186-16, de 24 de agosto de 2001.

CALDAS, Andressa. Regulação jurídica do conhecimento tradicional: a conquista dos saberes. Dissertação (Mestrado em Direito das Relações Sociais), Curso de Pós-graduação em Direito, Universidade Federal do Paraná, Curitiba, 2001.

CARNEIRO DA CUNHA, Manuela. Deve o conhecimento ser livre? A invenção da cultura e os direitos de propriedade intelectual. Revista Sexta-feira: Antropologia, Artes e Humanidades. São Paulo: Editora 34, n.3, outubro 1999.

CULLEN, Carlos. La construcción de un espacio público intercultural como alternativa a la asimetría de culturas en el contexto de la globalización: perspectivas latinoamericanas. In: FORNET-BETANCOURT, Raul. Culturas y poder: interacción y asimetría entre las culturas en el contexto de la globalización. Bilbao: Desclée de Brouwer, 2003.

DERANI, Cristiane. Patrimônio genético e conhecimento tradicional associado: considerações jurídicas sobre seu acesso. In, LIMA, André. (org.). O direito para o Brasil socioambiental. Porto Alegre: Sérgio Antonio Fabris Editor, 2002.

FONSECA, Maria Cecília Londres da. Para além da "pedra e cal": uma concepção ampla de patrimônio cultural. In: ABREU, Regina; CHAGAS, Mário (orgs.). Memória e patrimônio, ensaios contemporâneos. Rio de Janeiro: DP\&A, 2003.

HERRERA FLORES, Joaquín (org.). Hacía una visión compleja de los derechos humanos. In: HERRERA FLORES, Joaquín (org.) El vuelo de Anteo: derechos humanos y crítica de la razón liberal. Bilbao: Desclée de Brouwer, 2000.

KAINGANG, Azelene Inácio Kring. Memória: nossas conquistas através do conselho nacional de combate à discriminação. Brasília: fevereiro de 2003. 
LÉVI-STRAUSS, Claude. O pensamento selvagem. São Paulo: Edusp, 1970.

MORIN, Edgar. Introduction à la pensée complexe. Paris: ESF, 1990.

ONU. Informe del Grupo de Trabajo sobre la Aplicación del artículo $8 j$ y disposiciones conexas. UNEP/CDB/COP/5/5.

POSEY, Darrel. A ciência dos Mebêngôkre: alternativas contra a destruição. Belém: Museu Paraense Emílio Goeldi MPEG/CNPq, 1989.

SANTOS, Laymert Garcia dos. Propriedade intelectual ou direitos intelectuais coletivos? In: ARAÚJO, Ana Valéria; CAPBIANCO, João Paulo (Orgs.). Biodiversidade e proteção do conhecimento de comunidades tradicionais. Documentos do ISA - Instituto Socioambiental, 1996, n.2.

SOUSA SANTOS, Boaventura de. A crítica da razão indolente: contra o desperdício da experiência. In: Por um novo senso comum: a ciência, o direito e a política na transição paradigmática. 4.ed. São Paulo: Cortez, 2002. v.1.

; NUNES, João Arriscado. Para ampliar o cânone do reconhecimento, da diferença e da igualdade. In: SOUSA SANTOS, Boaventura (org). Reconhecer para libertar: os caminhos do cosmopolitismo multicultural. Rio de Janeiro: Civilização Brasileira, 2003.

SOUZA FILHO, Carlos Frederico Marés de. O renascer dos povos para o Direito. Curitiba: Juruá, 1998. . Bens Culturais e proteção jurídica. Porto Alegre: Unidade Editorial, 1999.

* Doutor em Direito das Relações Sociais. Professor e coordenador do Programa de Pós-graduação em Direito Ambiental da Universidade do Estado do Amazonas. Professor convidado do Programa de Doutorado Direitos Humanos e Desenvolvimento da Universidad Pablo de Olavide de Sevilla, Espanha. 